\title{
Impact of Procedure Specific Videos in the Performance of Restorative Procedures by Pre-Clinical dentistry Students
}

\author{
Sara Ikram Khan ${ }^{1}$ \\ BDS \\ Fasiha Moin Kazi \\ BDS \\ Shama Asghar ${ }^{3}$ \\ BDS, FCPS
}

OBJECTIVE: With the advances in technology the teaching process needs to be improved. Video assisted learning has become an integral part of effective teaching. Using procedural or instructional videos have shown to augment student's preparedness for real life clinical practice and helps them to improve their skills at their own pace and learning ability. The aim if this study was to assess the impact of procedure-specific video demonstrations on the performance of pre-clinical dentistry students.

METHODOLOGY: It was a cross-sectional experimental study conducted at the Pre-Clinical Operative Dentistry Phantom Lab at Bahria University Medical and Dental College Karachi, Pakistan. 50 students were divided equally into group A and group B (25 students in each group) by convenience sampling. Both groups prepared class 1 cavity and restored with amalgam. Group A were taught by a hands-on demonstration whereas Group B were taught by live demonstration as well as a procedurespecific video. The students were analyzed for the quality of their practical work as well as their understanding of key concepts. IBM statistics version 20 was used to carry out the statistical analysis. Pearson Chi Square test and independent T test were used, a p-value less than 0.05 was considered significant.

RESULTS: Group A's assessment regarding cavity preparation showed that majority students of the group ( $\mathrm{n}=11$ ) required crucial changes in cavity design. For group B most students $(n=9)$ reproduced important factors of cavity design however improvement was required. For amalgam filling, Group A and B's majority students had similar results. t-test was conducted and significant difference was found in the overall performance scores for group $\mathrm{A}(\mathrm{M}=6.7, \mathrm{SD}=1.7)$ and group $\mathrm{B}(\mathrm{M}=8.0$, $\mathrm{SD}=2.3$ ); t-test $\mathrm{p}=0.04$.

CONCLUSION: This study suggests that video assisted learning as an additional tool to traditional teaching, can augment understanding and learning process of students.

KEY WORDS: Video demonstration, Teaching methodology, Dental Education, Dental Undergraduates, Operative Dentistry. HOW TO CITE: Khan SI, Kazi FM, Asghar S. Impact of procedure specific videos in the performance of restorative procedures by pre-clinical dentistry students. J Pak Dent Assoc 2019;28(4):176-180.

DOI: https://doi.org/10.25301/JPDA.284.176

Received: 03 January 2019, Accepted: 22 July 2019

\section{INTRODUCTION}

$\mathrm{D}$ uring the course of dental education, students combine their theoretical knowledge, technical skills and artistic abilities to perform dental procedures. ${ }^{1}$ Training of Pre-clinical students is designed to provide students with a simulated environment where they can actively and efficiently learn and practice their clinical skills and form the foundations of working on live patients. ${ }^{2}$

1. Senior Registrar, Department of Operative Dentistry, Bahria University Medical and Dental College, Karachi.

2. Senior Registrar, Department of Operative Dentistry, Bahria University Medical and Dental College, Karachi.

3. Associate Professor, Department of Operative Dentistry,Bahria University Medical and Dental College, Karachi.

Corresponding author: "Dr. Sara Ikram Khan” < saraikramkhan90@gmail.com >
Traditionally students receive live clinical demonstration from an expert teacher who performs step by step clinical procedure which is then practiced on phantom teeth. ${ }^{3}$ Clinical demonstration is usually done in small group of students which is usually time consuming and detailed visualization might not be possible for all students. ${ }^{4}$

Observation of procedure is important and by any means if teachers can improve the learning process it will reduce the risk of procedural errors. ${ }^{3}$ With the advances in technology the teaching process needs to be improved. Video assisted learning has become an integral part of effective teaching. ${ }^{5}$ Using procedural or instructional videos have shown to augment student's preparedness for real life clinical practice and helps them to improve their skills at their own pace and learning ability. ${ }^{6}$ It helps in better visualization and offer simulation in variety of learning styles according to a student's 
preference and can be saved to be repeated multiple times. ${ }^{7}$

Several studies ${ }^{3,8,9}$ shows that video assisted learning has improved the learning curve of students. Ramlogan et $\mathrm{l}^{10}$ suggested it to be a positive supplement to traditional teaching ways.

Many international universities have their own web portals where lectures and tutorial videos are uploaded regularly for the use of their students. A trend like this not only makes it easy for students to gain access to authentic and reliable information but also provides them the convenience of accessing the material at any time and for multiple viewing. ${ }^{11}$

As the teaching of dentistry involves extensive preparation for psychomotor skills, clinical trials should be done to further explore student's output of video assisted learning. Therefore, the aim if this study was to assess the impact of procedure-specific video demonstrations on the performance of pre-clinical dentistry students.

\section{METHODOLOGY}

It was a cross-sectional experimental study conducted from July 2018 to October 2018 at the Pre-Clinical Operative Dentistry Phantom Lab at Bahria University Medical and Dental College Karachi, Pakistan. Ethical approval was obtained by the Ethical review committee of Bahria University Medical and Dental College Karachi (Ref. no: ERC 54/2018). 50 students of pre-clinical operative dentistry (2nd Year BDS) were included in the study and were randomly divided into group A and group B with 25 students in each group.

Firstly, students from both groups received a comprehensive 45-minute lecture on class 1 cavity preparation and restoration with amalgam, a week before their lab by a senior faculty member from the Department of Operative Dentistry. The students were also provided handouts of the lecture to facilitate better understanding. Students who were absent in the lecture session were excluded from the study. An assessment rubric was be prepared. (Annexure A) which served two purpose. Firstly, it was used by two pre-clinical dentistry instructors to judge the practical work of the students. Secondly, it was used to evaluate the knowledge of the students related to the content. This was done by giving the students a 5-stem multiple choice questionnaire in the next session.

On the lab day, Group A received a short 15-minute hands-on demonstration on class 1 cavity preparation by an instructor from the department. The students were then given 60 minutes to prepare a class 1 cavity on tooth \# 46 (mandibular first molar) of phantom teeth and were asked to label the prepared tooth with their roll number and submit it for evaluation by the instructors. (Annexure A) In the next session, the teeth were returned to the students to be restored with amalgam and handed over to the instructors for a final marking of the restorations. During the same session, the students filled 5 stem multiple choice questionnaire to assess their understanding of the subject matter. (Annexure B)

For Group B, a comprehensive 15-minute procedurespecific video was selected from You-Tube, covering the topics of Class 1 cavity preparation and Class 1 amalgam restoration. The video was first judged by the faculty of operative department for relevance and quality of content. The students were first given live demonstration like group A and then showed the video on their lab day. They were allotted 60 minutes to proceed with their cavity preparation accordingly and return the teeth to the instructors for evaluation. Similar to group A, the next session was conducted to restore the teeth with amalgam and questionnaire was filled out by the students.

All assessment was done by blinded subject instructors for both groups to avoid bias. Both groups worked in the same lab on their respective days and utilized the same dental materials. The students were analyzed on the basis of the quality of their practical work as well as their understanding and reproduction of key concepts related to the procedures.

The criteria for evaluation of Class 1 cavity was outline form including all pits \& fissure; depth of cavity, cavosurface margin, flat floor and rounded line angles. Evaluation criteria for amalgam filling was that cavity should be properly filled (not overfilled or underfilled), no flashes, no gaps in margins and occlusal anatomy is reproduced. Figure 1 shows summary of the whole protocol.

IBM Statistics version

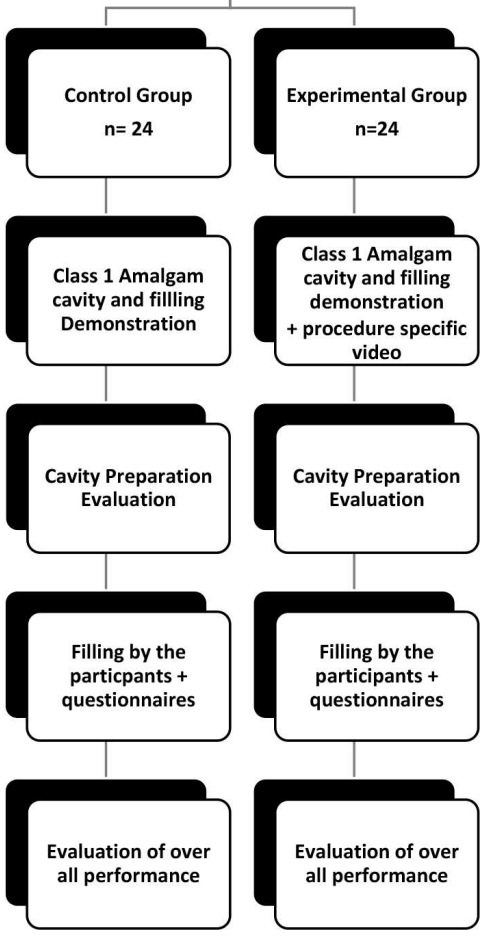

Fig 1: Summary of experimental protocol

20 was used to carry out the statistical analysis of the variables. Pearson Chi square test and Independent sample 
$\mathrm{t}$ test was applied to compare the conventional educational method with procedure specific video method. A p-value less than 0.05 was considered significant.

\section{RESULTS}

Our sample had $16.7 \%$ males and $83.3 \%$ females. Group A's $(n=24)$ assessment regarding cavity preparation (Table 1) showed that $46 \%$ students of the group $(n=11)$ required crucial changes in cavity design while $25 \%$ had flawed cavities $(n=6)$ and were asked to redo. For group B, $33 \%$ students $(\mathrm{n}=8)$ reproduced important factors of cavity design and $25 \%(\mathrm{n}=6)$ required crucial changes to be made. Among group B, $17 \%$ of the students reproduced all principles of cavity design which is higher in comparison to $4 \%$ of group A, however the differences between two groups were not statistically significant using Pearson Chi square test $\mathrm{p}$ value $>0.05$.

For amalgam filling, Group A and B didn't show statistically significant difference but group B's performance

Table 1: Table showing cavity preparation assessment score of students in both groups

\begin{tabular}{|c|c|c|c|c|}
\hline Scores & Cavity Preparation & $\underset{(n)^{*}}{\operatorname{Group} A}$ & $\underset{\text { (n) }}{\text { Group B }}$ & $P$-value \\
\hline 4 & $\begin{array}{l}\text { All principles of cavity design are followed to the best of } \\
\text { the student's ability; design will appear flawless after } \\
\text { finishing. }\end{array}$ & 1 & 4 & \multirow{4}{*}{0.1} \\
\hline 3 & $\begin{array}{l}\text { Important factors in design are reproduced; however, } \\
\text { improvement is required }\end{array}$ & 5 & 8 & \\
\hline 2 & $\begin{array}{l}\text { Important factors in design are ignored. Crucial changes } \\
\text { are required. }\end{array}$ & 11 & 6 & \\
\hline 1 & $\begin{array}{l}\text { Cavity appears flawed. Needs to be prepared on another } \\
\text { tooth }\end{array}$ & 7 & 6 & \\
\hline
\end{tabular}

*(n) number of students to score the particular criteria of cavity preparation in group $A$ and $B$

Table 2: Table showing amalgam filling assessment score of students in both groups

\begin{tabular}{|c|c|c|c|c|}
\hline Scores & Amalgam Restoration & $\begin{array}{c}\text { Group } A \\
(n)^{*}\end{array}$ & $\begin{array}{c}\text { Group B } \\
(\mathrm{n})\end{array}$ & P Value \\
\hline 4 & $\begin{array}{l}\text { Restoration appears smooth and shiny with neat margins; } \\
\text { occlusal anatomy needs to be reproduced properly. }\end{array}$ & 1 & 3 & \multirow{4}{*}{0.3} \\
\hline 3 & $\begin{array}{l}\text { Restoration margins appear smooth but irregular with } \\
\text { amalgam flash present. Adequate carving and burnishing can } \\
\text { improve it. }\end{array}$ & 4 & 8 & \\
\hline 2 & $\begin{array}{l}\text { Restoration appears underfilled; marginal integrity not } \\
\text { present. Major corrections required }\end{array}$ & 16 & 9 & \\
\hline 1 & $\begin{array}{l}\text { Restoration appears flawed. Need to be repeated from } \\
\text { scratch. }\end{array}$ & 3 & 4 & \\
\hline
\end{tabular}

*(n) number of students to score the particular criteria of amalgam filling in group $A$ and $B$

Table 3: Table showing concept assessment score of students in both groups.

\begin{tabular}{|l|c|c|c|c|}
\hline \multicolumn{1}{|c|}{ Study Groups } & N & Mean & SD & P-Value \\
\hline Group A & 24 & 6.7 & 1.7 & \multirow{2}{*}{$0.04^{*}$} \\
\hline Group B & 24 & 8.0 & 2.3 & \\
\hline
\end{tabular}

$*(n)$ number of students to score the particular criteria of concepts in group $A$ and $B$ was better as 33\% of group B performed smooth restorations as compared to group A where only $14 \%$ had smooth restorations (Table 2). 67\% of group A had underfilled cavities with absence of marginal integrity in comparison with group B's $37 \%$.

Regarding understanding of key concepts most students of group A had clear concepts but not completely understood while in Group B, 37.5\% ( $n=9)$ had clear concepts and completely understood the concepts (Table 3 ).

An independent samples t-test was conducted to compare the performance in terms of total scores in group A and B. There was a significant difference in the overall performance scores for group $\mathrm{A}(\mathrm{M}=6.7, \mathrm{SD}=1.7)$ and group $\mathrm{B}(\mathrm{M}=8.0$, $\mathrm{SD}=2.3$ ); t-test $\mathrm{p}=0.04$ (Table 4 ). These results suggest that

Table 4: Independent samples t-test shows significant difference in the overall performance scores for group $\mathrm{A}$ and $\mathrm{B}$ with a $P$ value of $<0.05$

\begin{tabular}{|c|c|c|c|c|}
\hline Scores & Understanding of Key Concepts & $\underset{(n)^{*}}{\operatorname{Group} A}$ & $\underset{(n)}{\text { Group B }}$ & P-Value \\
\hline 4 & $\begin{array}{l}\text { Concepts are clear and completely understood. The } \\
\text { major steps of cavity preparation and restoration } \\
\text { are understood }\end{array}$ & 3 & 9 & \multirow{4}{*}{0.2} \\
\hline 3 & $\begin{array}{l}\text { Concepts are clear but not completely understood. } \\
\text { Need for discussion to aid in understanding. Steps of } \\
\text { cavity preparation and restoration need to be revised }\end{array}$ & 10 & 9 & \\
\hline 2 & $\begin{array}{l}\text { Poor understanding of key concepts as well as the } \\
\text { steps of cavity design and restoration. }\end{array}$ & 10 & 6 & \\
\hline 1 & $\begin{array}{l}\text { Extremely vague ideas of the subject matter. Total } \\
\text { lack of comprehension. }\end{array}$ & 1 & 0 & \\
\hline
\end{tabular}

students who were shown procedural video in addition to demonstration (Group B) performed better than the other group (Group A).

\section{DISCUSSION}

The use of information technology for learning purposes has increased by leaps and bounds globally after the introduction of the internet and the availability of video lectures and tutorials. Educators are updating the modalities and simulation techniques to enhance efficiency in delivering knowledge to students effectively and in less amount of time. ${ }^{12}$ Dental curricula in pre-clinical operative dentistry uses phantom head manikins or a typodont tooth to allow students to practice before doing actual patients in senior years. ${ }^{13}$

The results of our study show that students who were given demonstration and shown video of the procedure covering all the technical details showed over all better performance. These results agree with studies done by Rosa et $\mathrm{al}^{14}$, Mirkarimi et al ${ }^{15}$, Nikzad et $\mathrm{al}^{16}$, Rystedt et al ${ }^{17}$; who concluded that procedural videos have shown to be as effective as live procedure demonstration by an instructor. This is particularly helpful to alleviate common problems of teachers who are challenged with little laboratory time while teaching large number of students. ${ }^{7}$ The other advantage 
is that the video demonstration teaches students in uniformity and in a well-structured manner. ${ }^{18}$

In our study, the students who also saw the video were able to better visualize the procedure and hence a greater number of students were better able to repeat the procedure performed on typodonts. This was also concluded by studies done by Packer et $\mathrm{al}^{19}$ and Aragon et $\mathrm{al}^{20}$ who evaluated that video shown on plasma screen to undergraduates was a great teaching tool.

Even though in our study, the over-all performance of second group was better but the differences were not found to be highly significant which shows that traditional teaching methods also provide similar levels of understanding and videos if used as an adjunct can help in better performance. Similar conclusions were stated by Nasseri et $\mathrm{al}^{3}$, Alqahtani et $\mathrm{al}^{7}$, Mirkarimi et $\mathrm{al}^{21}$ who suggested combination of both the methods.

The limitation of this study was that it had a small experimental group and was undertaken at one dental school only. Video assisted learning needs to be evaluated on larger group of students to assess the sustainability of this teaching modality. There needs to be a balance in live teaching and video assisted teaching to maintain the element of interaction between student and teacher.

\section{CONCLUSION}

In our study, more students showed better understanding and performance after watching procedural videos in addition to traditional demonstration by the instructor however the differences were not significant and traditional teaching methods are equally effective. This study suggests that video assisted learning as an additional tool to traditional teaching, can augment understanding and learning process of students where they can accurately assess the skills that are required to perform a certain procedure and learn the desired outcome.

\section{SUGGESTIONS}

The world is pacing towards technological advancement in every field. Educators need to update the strategies to train pre-clinical students to the best of their abilities. Therefore, live demonstration and modern teaching methods such as video assisted learning should be inculcated in dental curricula of pre-clinical students for better results in their clinical practice.

\section{CONFLICT OF INTEREST}

No conflict of interest was reported.

\section{REFERENCES}

1: Shah DY, Dadpe AM, Kalra DD, Garcha VP. Videotaped Feedback Method to Enhance Learning in Preclinical Operative Dentistry: An Experimental Study. J Dent Educ. 2015;79:1461-66.

2: Reissmann DR, Sierwald I, Berger F, Heydecke G. A model of blended learning in a preclinical course in prosthetic dentistry. J Dent Educ. 2015;79:157-65.

3: Naseri M, Shantiaee Y, Rasekhi J, Zadsirjan S, Bidabadi MM, Khayat A. Efficacy of Video-Assisted Instruction on Knowledge and Performance of Dental Students in Access Cavity Preparation. Iranian endod. 2016;11:329.

4: Aragon CE, Zibrowski EM. Does exposure to a procedural video enhance preclinical dental student performance in fixed prosthodontics? J Dent Educ. 2008;72:67-71.

5: Fakhry A, Cooper S, Slach N, Krenz S. Video-assisted clinical instruction in dentistry. Overview and applications. Eur J Dent Educ. 2007;11:230-37.

https://doi.org/10.1111/j.1600-0579.2007.00461.x

6: Pilieci SN, Salim SY, Heffernan DS, Itani KM, Khadaroo RG. A Randomized Controlled Trial of Video Education versus Skill Demonstration: Which Is More Effective in Teaching Sterile Surgical Technique? Surgi infect. 2018;19:303-12.

https://doi.org/10.1089/sur.2017.231

7: Alqahtani ND, Al-Jewair T, Khalid AM, Albarakati SF, ALkofide EA. Live demonstration versus procedural video: a comparison of two methods for teaching an orthodontic laboratory procedure. BMC Med Educ. 2015;15:199.

https://doi.org/10.1186/s12909-015-0479-y

8. Rystedt H, Reit C, Johansson E, Lindwall O. Seeing Through the Dentist's Eyes: Video-Based Clinical Demonstrations in Preclinical Dental Training. J Dent Educ. 2013;77:1629-38.

9. Fakhry A, Dehkordi-Vakil FH. Video-Assisted Clinical Instruction in Dentistry (VACID) enhances real-time visualisation of clinical procedures. Eur J Dent Educ. 2007;11:238-44.

https://doi.org/10.1111/j.1600-0579.2007.00465.x

10. Ramlogan S, Raman V, Sweet J. A comparison of two forms of teaching instruction: video vs. live lecture for education in clinical periodontology. Eur J Dent Educ. 2014;18:31-8.

https://doi.org/10.1111/eje.12053

11. Jonach R, Ebner M, Grigoriadis Y. Automatic System for Producing and Distributing Lecture Recordings and Livestreams Using Opencast Matterhorn. J Educ Issues. 2015;1:150-58.

https://doi.org/10.5296/jei.v1i2.8653

12. Perry S, Bridges SM, Burrow MF. A review of the use of simulation in dental education. Simulation Healthcare. 2015;10:31-7. https://doi.org/10.1097/SIH.0000000000000059

13. Roy E, Bakr MM, George R. The need for virtual reality simulators 
in dental education: a review. Saudi Dent J 2017;29:41-7. https://doi.org/10.1016/j.sdentj.2017.02.001

14. Rosa QF, Barcelos TM, Kaizer MR, Montagner AF, Sarkis-Onofre R, Masotti AS, et al. Do educational methods affect students' ability to remove artificial carious dentine? A randomised controlled trial. Eur J Dent Educ. 2013;17:154-58.

https://doi.org/10.1111/eje.12028

15. Mirkarimi M, Arbabi Kalati F, Ansari Moghadam A. A comparison between video tape and live demonstration methods for teaching of fissure sealant placement procedures for dental students of Zahedan University of Medical Sciences in 2010-2011. J Dent Medi. 2011;24:252-57.

16. Nikzad S, Azari A, Mahgoli H, Akhoundi N. Effect of a procedural video $\mathrm{CD}$ and study guide on the practical fixed prosthodontic performance of Iranian dental students. J Dent Educ. 2012;76:354-59.

17. Rystedt H, Reit C, Johansson E, Lindwall O. Seeing Through the Dentist's Eyes: Video-Based Clinical Demonstrations in Preclinical Dental Training. J Dent Educ. 2013;77:1629-38.
18. Packer ME, Rogers JO, Coward TJ, Newman PS, Wakeley R. A comparison between videotaped and live demonstrations, for the teaching of removable partial denture procedures. Eur J Dent Educ. 2001;5:17-22.

https://doi.org/10.1034/j.1600-0579.2001.005001017.x

19. Packer ME, Coward TJ, Wakeley R, Fenlon MR. A preliminary study to investigate the potential of plasma screen technology in small group teaching for dental undergraduates. Eur J Dent Educ. 2003;7:13642.

https://doi.org/10.1034/j.1600-0579.2003.00295.x

20. Aragon CE, Zibrowski EM. Does Exposure to a Procedural Video Enhance Preclinical Dental Student Performance in Fixed Prosthodontics? J Dent Educ. 2008;72:67-71.

21. Mirkarimi M, Arbabi Kalati F, Ansari Moghadam A. A comparison between video tape and live demonstration methods for teaching of fissure sealant placement procedures for dental students of Zahedan University of Medical Sciences in 2010-2011. J Dent Medi. 2011;24:252-57 . 